vez maior de drogas tem sido incriminado no desencadeamento de pseudolinfoma cutâneo. 0 caso apresentado evidencia a possibilidade de pseudolinfoma induzido por drogas, com histopatológico semelhante a linfoma, cuja avaliação imuno-histoquímica e molecular ofereceu importante auxílio diagnóstico.

Motivo dA APRESENTAÇÃo: Raridade do caso e importância do diagnóstico diferencial.

\title{
DEPARTAMENTO DE BIOLOGIA E GENÉTICA MOLECULAR
}

\section{P066 Eritroqueratodermia congênita simétrica progressiva}

\author{
AUTORES: $\quad$ Silveira-Sousa D, Yuge S, Romanine AM, Godoi DAS, Barreto JA. \\ INSTITUIÇÃO: Instituto Lauro de Sousa Lima - Bauru, SP.
}

INTRODUÇão: As eritroqueratodermias são genodermatoses raras com amplo espectro de manifestações clínicas e evolutivas e caracterizam-se por placas hiperqueratóticas com bases eritematosas. A eritroqueratodermia congênita simétrica progressiva (EQSP) caracteriza-se pela presença de lesões não variáveis, com distribuição característica.

Relato do Caso: Criança de 2 anos e 10 meses de idade, com história de apresentar aos primeiros meses, eritema difuso da pele associado à descamação fina, que logo evoluiu com placas recobertas por escamas espessas e aderidas, com halo eritematoso periférico. O quadro tem períodos de melhora transitória e recorrência das lesões nos mesmos locais, com intensificação do quadro, principalmente, no último ano. Não apresentava relato de nascimento, como "bebê colóide". Desenvolvimento neuro-psico-motor compatível com a normalidade. Não apresentava história familiar de dermatoses. Ao exame dermatológico, observavam-se placas hiperqueratóticas, com limites nítidos, contorno irregular, bem demarcados, tamanhos variados, formando mosaico, simétricas, com presença de halo eritematoso delimitando as lesões; superfície recoberta por escamas espessas, aderentes, amarronzadas e secas. Localizavam-se, preferencialmente, em face, coxas e porção extensora dos membros. Não apresentava acometimento palmo-plantar e em região flexural. Avaliação laboratorial compatível com a normalidade. Exame histopatológico evidenciou hiperplasia epitelial regular, hiperqueratose alternado com paraqueratose, papilomatose, discreto infiltrado mononuclera perivascular. A criança foi tratada inicialmente com retinoides tópicos com melhora parcial do quadro, diminuição da espessura das placas e da área de comprometimento da lesão.

Dıscussão: A EQSP foi descrita inicialmente descrita por Darier em 1911 e, desde então, poucos casos têm sido descritos na literatura. É transmitida por herança autossômica dominante, com penetrância incompleta e expressividade variável. Ambos os sexos são acometidos de forma igual. As lesões tendem a localizar-se, principalmente, nas extremidades, nádegas e face. 0 tronco tende a ser poupado e a região palmo plantar pode ser comprometida em cerca de metade dos casos. As lesões podem surgir ao nascimento ou nos primeiros meses de vida, tendendo à estabilização durante a puberdade, com relato de remissão espontânea. 0 tratamento pode ser feito com retinóides orais pesando-se os efeitos colaterais, principalmente com relação ao crescimento. A melhora clínica com o uso de retinóides tópicos é controversa na literatura, apesar de nossa paciente ter tido resposta satisfatória. Medicações tópicas ceratolíticas e hidratantes podem contribuir para o controle do quadro.

Motivo DA APRESENTAÇÃO: Descrição dos achados clínicos, histológicos e evolutivos da EQSP com base nos conhecimentos científicos atuais.

\section{P067 Esclerose tuberosa: caso clássico com tumor de Köenen exuberante}

\author{
AUTORES: Azevedo WAS, Processi DP, Albuquerque GC,Oliveira CR, Quinete SS. \\ INSTITUIÇÃO: Hospital Central do IASERJ - Rio de Janeiro, RJ
}

INTRODUÇÃo: Esclerose tuberosa ou Síndrome de Pringle-Bourneville ou EPILOIA é uma genodermatose autossômica dominante de penetrância variável, afeta 1 em 6.000 indivíduos e é caracterizada pela tríade de VOGT (Epilepsia, Retardo mental e Adenoma).

Relato do Caso: História: M.J.A.A., masculino, branco, 18 anos, solteiro, natural do Rio de Janeiro, RJ, procedente de Irajá, RJ. HDA: Paciente com história de 1 a crise convulsiva aos 3 meses de idade, atraso de desenvolvimento psico-motor, lesões dermatológicas e alterações eletroencefalográficas no 10 ano de vida "SIC", apresentando lesão tumoral de evolução lenta, início há 10 anos, em hálux direito e surgimento de 
lesão semelhante em $2^{\circ}$ quirodáctilo direito recentemente. ISDA: hiperatividade com déficit intelectual e atrofia óptica. HF: não há referência de casos na família. Exame Clínico: observam-se em membros superiores, inferiores e tronco máculas hipomelanóticas; placa irregular espessada de $6 \mathrm{~cm}$ na região lombossacra desde os 18 meses de vida; pápulas menores que $0,5 \mathrm{~cm}$ de cor amarelo-avermelhadas na porção central da face de início na puberdade; projeções exuberantes de coloração rósea que emergem de dobras ungüeais medindo $3 \mathrm{~cm}$ em hálux direito e 0,5-1 cm em 2o pododáctilo direito. Exames Complementares: TC de crânio: calcificações periventriculares e proliferação glial. Tratamento: sintomático, optado por não abordagem cirúrgica do tumor Köenen e anticonvulsivantes orais.

Dıscussão: Esclerose tuberosa é doença genética decorrente da inativação de gens TSC 1 e TSC 2 em células germinativas e somáticas, afetando principalmente os sistemas nervoso e dermatológico. 0 paciente em relato apresenta angiofibromas, fibromas periungueais, Shagreen patches e máculas hipomelanóticas ( 4 critérios diagnósticos maiores), além de convulsões, calcificações, proliferação glial e retardo mental caracterizando um quadro típico de Esclerose Tuberosa. Sistemicamente, pode haver hamartomas em rim, fígado, tireóide, pâncreas e outros órgãos, rabdomiomas cardíacos e facomas na retina. Aconselhamento genético é fundamental. 0 tratamento é sintomático. 0 prognóstico além da 3a década é sombrio.

Motivo DA APRESENTAÇÃo: Descrição de um caso quadro típico de uma genodermatose relativamente rara acrescido de tumor de Köenen de dimensões exuberantes.

\title{
P068 Hiperqueratose focal acral
}

\author{
AUTORES: $\quad$ Macedo DM, Nicoliello JM, Oda PN, Michalany NS, Rotta O. \\ INSTITUIÇÃO: UNIFESP - Escola Paulista de Medicina - São Paulo, SP.
}

INTRODuÇão: A Hiperqueratose focal acral (HFA) é uma genodermatose rara, de etiologia desconhecida, descrita em 1983 por Dowd como uma variante da acroqueratoelastoidose de Costa (AQE). De incidência esporádica, as lesões têm início geralmente antes dos 20 anos e não há predileção por raça ou sexo. 0 quadro clínico mostra pequenas pápulas assintomáticas, hiperqueratósicas e crateriformes que caracteristicamente se localizam ao longo das margens das mãos e pés num padrão de "pedras de calçamento".

Relato do Caso: Paciente de 71 anos, masculino, negro, refere prurido generalizado há cinco anos com melhora parcial com uso de emolientes e hidroxizine. 0 exame dermatológico mostrou xerose cutânea difusa, pápulas hiperqueratósicas com centro umbilicado na face lateral e medial de ambos os pés e hiperqueratose na região de inserção do tendão calcâneo. Os exames complementares foram normais e o exame histopatológico mostrou hiperqueratose focal compatível com queratodermia punctata sem alteração das fibras elásticas.

Dıscussão: 0 caso exposto apresenta-se com as lesões típicas acometendo as bordas laterais dos dedos das mãos e bordas e dorso dos pés e o exame histológico confirmou os achados de hiperqueratose focal sem elastorrexe, estabelecendo-se um diagnóstico de HFA. O diagnóstico diferencial é extenso, inclui principalmente a AQE e queratoelastoidose marginal. A HFA e a AQE compartilham as mesmas características clínicas e alterações histológicas da epiderme (sem elastorrexe na HFA), mas não há certeza sobre se as duas doenças estão patogeneticamente relacionadas. A queratoelasto idose, um outro diferencial, ocorre em pessoas acima de 60 anos, incide principalmente na borda radial do indicador e na borda medial do primeiro quirodáctilo em trabalhadores manuais expostos ao sol cronicamente. A HFA é uma doença benigna, de evolução crônica das lesões assintomáticas, de tratamento difícil e inefetivo, podem ser tentados queratolíticos tópicos e etretinato sistêmico com pouca melhora e recidiva freqüente.

Motivo dA APRESENTAÇão: Demonstração pela raridade do caso.

\section{P069 Síndrome de Klippel-Trénaunay - Relato de caso}

AUTORES: Processi DP, Azevedo WAS, Albuquerque GC, Carvalho CRCS, Quinete SS.

INSTITUIÇÃO: Serviço de Dermatologia do Hospital Central do IASERJ - Rio de Janeiro, RJ.

INTRODUÇÃo: A Síndrome de Klippel-Trénaunay é uma anomalia congênita rara, descrita inicialmente em 1900 e definida classicamente pela tríade de manchas vasculares, hipertrofia óssea ou de partes moles e má formações vasculares.

Relato de Caso: A.F.L., 55 anos, masculino, pardo, casado, desempregado, natural do Espírito Santo. 
Paciente refere aumento do volume do membro inferior direito há mais de 50 anos, associado a múltiplos cordões varicosos, negando dor, prurido, sangramento e episódios prévios de trombose e infecção secundária. História de cirurgia para correção de varizes com manutenção do quadro, associado apresenta cirrose hepática de provável etiologia alcoólica. Exame Clínico Geral: abdômen ascítico, circulação colateral tipo porto-cava com estigmas de insuficiência hepática. Exame Dermatológico: aumento difuso do membro inferior direito, associado a hemangioma comprometendo todo o membro. Exames Complemetares: anemia macrocítica, associado a leucopenia e trombocitopenia (hiperesplenismo), Rx MID com hipertrofia óssea, Tc Abdômen, com fígado irregular de aspecto cirrótico e esplenomegalia homogênea. EDA com varize de esôfago de médio calibre. A conduta terapêutica foi expectante com paciente evoluindo ao óbito em ago./04 por complicações decorrentes da cirrose hepática (hemorragia por varize de esôfago).

Dıscussão: Relatamos um caso que apresenta a tríade clássica da Síndrome de Klippel-Trénaunay, com a presença de hemangioma plano, aumento do volume do membro acometido com hipertrofia óssea e alterações vasculares. Alguns autores consideram que a síndrome é causada por uma anormalidade mesodérmica generalizada e que a atresia do sistema venoso profundo seria mais um componente desta. A maioria dos casos é de ocorrência esporádica, mas poucos casos podem apresentar um componente familiar. As complicações dependem do órgão acometido e incluem trombose, celulite e também comprometimento psicológico devido ao aspecto desfigurante da patologia. 0 tratamento pode se feito com ablação vascular com laser, correção cirúrgica e o uso de meias elásticas principal mente nos pacientes com comprometimento linfático e venoso extenso.

Motivo DA APRESENTAÇÃo: Raridade de ocorrência desta patologia.

\title{
PO 70 Neurofibromatose segmentar: relato de caso
}

\author{
AUTORES: $\quad$ Almeida AT, Loures SA, Chiacchio ND, Finamor DC, Michalany NS. \\ INSTITUIÇÃO: Hospital do Servidor Público Municipal de São Paulo - São Paulo, SP.
}

INTRODUÇÃo: Os neurofibromas manifestam-se como lesões solitárias ou no contexto da neurofibromatose. Surgem em nervos e podem ser observados em qualquer trajeto nervoso. Os de localização cutânea apresentam-se como lesões de protuberantes a pedunculadas, nódulos ou pápulas cor salmão, tipicamente amolecidos à pal pação. Podem ser muito pruriginosos.

Relato do CaSo: H.D., 51 anos, masculino, branco, casado, assistente técnico, natural e procedente de São Paulo. Doente refere que há 2 anos notou aparecimento gradual de lesões assintomáticas na região frontal direita que se estenderam para o dorso do nariz. História Patológica Pregressa: HAS e gota. Trauma no olho D com amaurose, aos 3 anos, e uso de prótese ocular desde os 22 anos. Ao exame dermatológico observam-se pápulas e nódulos discretamente eritematosos, bem delimitados, apresentando superfície lisa com telangiectasias e amolecidos com até $1,5 \mathrm{~cm}$ de diâmetro, nas regiões frontal, glabelar e asa nasal direita, com disposição zosteriforme. Exames Complementares: RX e TC crânio: sem alterações. FO: presença de lesão cicatricial macular por trauma. Ao exame Histopatológico: na derme presença de neoplasia benigna de natureza neural constituída por células com núcleos alongados e sinuosos, citoplasma eosinófilo e fibrilar, distribuídas desordenadamente, tendo de permeio capilares sanguíneos também proliferados e mastócitos. Não há sinais de malignidade.

Dıscussão: A neurofibromatose subdivide-se em oito tipos. A forma segmentar (NF-V) é uma variante pouco relatada, mais freqüente no sexo feminino, caracterizada pela presença de neurofibromas e/ou manchas café-com-leite limitados a segmentos circunscritos, geralmente um dermátomo, ausência de manifestações sistêmicas e história familiar negativa. A localização mais freqüentemente acometida é o tronco. A maior parte dos casos de NF-V não tem padrão hereditário, resulta da mutação somática pós-zigótica, atingindo um lócus funcional e se manifestando ao nível da crista neural. 0 tratamento é conservador; a cirurgia é reservada para lesões desfigurantes, que causem dano funcional, dor ou crescimento rápido.

Motivo da APRESENTAÇÃo: Raridade do caso. 


\title{
Paquioníquia congênita associada à alopécia
}

\author{
AUTORES: Cavinato LB, Coelho DSS, Pereira ERD, Silva AA, Lima SS. \\ INSTITUIÇÃO: Hospital Infantil Darcy Vargas - São Paulo, SP.
}

\begin{abstract}
INTRODução: Paquioníquia Congênita é definida como uma displasia éctodermica de herança geralmente autossômica dominante. É uma genodermatose ligada a mutação dos genes (K6A, K16 e K6B, K17) que codificam a queratina, tendo como características unhas hiperceratósicas, que surgem após o nascimento, com desprendimento do leito ungueal e assumem coloração amarelo acastanhada. Podem surgir hiperqueratose palmo plantar, ceratose folicular, presença de veiculas e bolhas nos pés, hiperhidrose, anormalidade dos cabelos, leucoceratose da mucosa oral, alterações oculares, cisto epidermóide e outras anomalias: espina bífida, diverticulose e alterações cardíacas. Alopécia pode estar presente em $10 \%$ dos casos.
\end{abstract}

Relato do Caso: Paciente J.B.J., 10 anos, negro, natural da Bahia, procedente de São Paulo, SP, apresenta espessamento das 20 unhas, iniciado nos primeiros meses de vida, com surgimento de lesões vésico-bolhosas em ambos os pés com predileção pelas plantas e ausência de pelos.

Exames Complementares: Hemograma, RX de crânio, RX de tórax normais, RX de mãos e punhos com idade óssea normal, micológico direto das unhas revelou-se negativo, citologia do líquido das vesículas do pé direito sem celularidade. Exame dermatológico - espessamento das lâminas ungueais das 20 unhas, hiperqueratose sub-ungueal, unhas de coloração amarelo-acastanhada, hiperqueratose palmo-plantar, hiperidrose plantar, não apresentando vesículas ou bolhas no momento e com alopécia universal. Exames histopatológicos: a) couro cabeludo - corte mostra oito folículos pilosos, seis deles com diminuição do tamanho e um com discreto infiltrado inflamatório linfocitário ao redor do bulbo capilar; b) região plantar - camada córnea acentuadamente espessada e compacta com focos de paraqueratose. Tratamento: uso de ceratolíticos locais e de vitamina A sistêmica com temporária melhora das lesões.

Discussão e Conclusão: A paquioníquia congênita é uma síndrome difícil de ser classificada. Isso se deve ao grande número de sinais decorrentes dessa genodermatose, gerando dúvidas nas classificações existentes. 0 caso relatado demonstra essas deficiências, pois observamos alterações de ambas as síndromes (JadassonhLewandowsky e Jackson-Lawler), acrescentando sinais como alopecia universal, que acomete apenas $10 \%$ dos pacientes, segundo a literatura, o que nos leva a observar que o fundamental não é classificar e sim diagnosticar, pois só assim faremos uma correlação multidisciplinar, dando qualidade de vida ao nosso paciente. Motivo DA APRESEnTAÇÃo: Relato de caso clínico a fim de destacar a raridade da patologia e a sua difícil classificação.

\section{PO 72 Parry Romberg x Barraquer-Simons}

AUTORES: Andrade FC, Martins PB, Dornelles LA, Sapiro L, Dornelles SIT.
INSTITUIÇÃO: Ambulatório de Dermatologia Sanitária - SES/RS - Porto Alegre, RS.

INTRODução: Apresentar caso de dismorfia hemifacial e aventar possíveis diagnósticos diferenciais.

ReLATO do CASO: H.S., 14 anos, masculino, fototipo IV, estudante, residente e procedente de São Luiz Gonzaga, RS. Há quatro anos apresenta alteração distrófica e dismórfica na hemiface direita de caráter assintomático e progressivo, sem fator desencadeante aparente. Nega qualquer história de traumatismo local, infecções, uso de medicações ou antecedentes familiares. Na análise inicial, não apresentava déficit motor ou sensitivo local, alteração neurológica, auditiva ou visual. Exame Físico: paciente apresenta acentuada lipoatrofia na hemiface direita, com desaparecimento total da "bolsa adiposa de Bichat". Não se notam alterações esclerodermiformes, assim como alterações que caracterizem atrofia epitelial. Exame Odontológico: alterações na região maxilar superior à direita com comprometimento da oclusão dentária. Durante a investigação radiológica foram encontrados os seguintes resultados: tomografia computadorizada do crânio normal; eletromiografia dos músculos frontal, da órbita pal pebral, nasal compressor, labial superior e inferior - inexistência de lesão nervosa motora periférica; Rx seios da face - normal; Rx crânio - discreta depres são do ramo lateral direito da mandíbula, associada à redução de partes moles locais. Realizados hemograma, glicemia em jejum, FAN e frações do complemento (C3-C4), anti-DNA, E Q U e creatinina. Histopatologia: derme com discreto infiltrado inflamatório linfocitário, leve atrofia folicular e diminuição de tecido subcutâneo. Não foi observada alteração epidérmica. 
Dıscussão: Inicialmente, por se observar somente lipoatrofia, sem alterações esclerodermiformes, foi levantada a hipótese clínica de Síndrome de Barraquer-Simons. A partir da disponibilização do dado radiológico de alteração mandibular, consideramos a possibilidade de Síndrome de Parry-Romberg com apresentação atípica, gerando discussão sobre diagnósticos diferenciais e possíveis intervenções terapêuticas.

MotIVo DA APRESENTAÇÃo: Raridade do caso com apresentação atípica.

\title{
PO 73 Cutis verticis gyrata
}

\author{
AUTORES: Dias TS, Shibuya MD, Magnago AGP, Leal JV, Lyon AC. \\ INSTITUIÇÃO: Hospital Eduardo de Menezes - Centro de Referência Estadual em Dermatologia Sanitária - \\ Fundação Hospitalar do Estado de Minas Gerais (FHEMIG) - Belo Horizonte, MG.
}

INTRODuÇão: Cutis Verticis Gyrata é um distúrbio congênito ou adquirido, caracterizado por excesso de pele no couro cabeludo, produzindo dobras espessas. Pode ser manifestação isolada, presente ao nascimento, ou ser parte de uma variedade de síndromes. Pode ser idiopática, associada a distúrbios endócrinos e/ou associada às seguintes síndromes: Paquidermoperiostose, Síndrome de Beare-Stevenson, Síndrome de Turner. O quadro é progressivo. Pode ainda ser encontrado retardo mental e epilepsia de difícil controle. Não há tratamento efetivo.

Relato do Caso: Os autores relatam o caso de um paciente, 45 anos, sexo masculino, apresentando quadro dermatológico de placas infiltradas em couro cabeludo, com leve descamação e eritema em vértice, há um ano e meio. Concomitantemente, apresentando acromegalia e diabetes mellitus. A histopatologia mostrou achados não característicos, incluindo fibrose dérmica, com espessamento discreto das fibras colágenas, infiltrado inflamatório linfo-histiocitário discreto na derme reticular e presença de reação periostial.

Dıscussão: Conforme descrito na literatura, o caso apresentado apresentou a lesão dermatológica associada a endocrinopatia e acromegalia.

MOTIVO DA APRESENTAÇÃo: Raridade da patologia.

\section{PO 74 Poroqueratose de Mibelli}

AUTORES: $\quad$ Heras C, Mantovani K, Martelotte M, Rabay F, Campana M.

INSTITUIÇÃO: Serviço de Dermatologia do Dr. Samuel H. Mandelbaum - Taubaté, SP.

INTRODUÇÃO: A poroqueratose de Mibelli é uma dermatose rara, crônica e hereditária, transmitida como traço autossômico dominante irregular. As lesões se desenvolvem como placas ásperas, anulares, circundadas por margens queratósicas elevadas. 0 centro é geralmente atrófico, mas pode ser hiperqueratósico ou normal. Aparecem com freqüencia nos membros e mostram tendência à disseminação centrífuga. A face, a genitália, a mucosa oral e a córnea podem também ser afetadas. A relação homem/mulher é de 3:1. Há risco de transformação maligna e lesões quiescentes podem tornar-se ativas mediante imunossupressão. A presença da lamela cornóide é a principal característica para o diagnóstico histopatológico.

HistóRIA: L.A.S., 19a, fem., procedente de Piquete, SP, com "manchas ásperas" próximas aos lábios há um ano. Exame Clínico: Pápulas precisamente próximas às comissuras labiais, progredindo centrifigamente ao longo de um ano, em placas com bordas circinadas e queratósicas. Diante de tal morfologia, foram realizadas as seguintes hipóteses diagnósticas: candidíase mucocutânea crônica, sífilis secundária (sifílides elegantes) lúpus eritematoso cutâneo crônico e poroqueratose de Mibelli. Exames Complementares: Histopatologia epiderme irregularmente espessada por acantose de cristas além de hiperqueratose e fina coluna de paraqueratose, reconhecida como lamela cornóide. Derme com infiltrado linfocitário difuso e pesquisa para fungos e PAS negativas. Portanto, compatível com poroqueratose. Tratamento: Ácido retinóico tópico.

Dıscussão: Neste caso, a poroqueratose de Mibelli desenvolveu-se como é descrito pela literatura, embora tenha se apresentado em uma local ização atípica e numa paciente feminina sem antecedentes familiares ou imunossupressão. Embora a terapêutica mais utilizada seja o 5- fluoracil tópico ou retinóides sistêmicos, optamos pelo tratamento com o ácido retinóico tópico.

Motivo DA APRESENTAÇ̃̃o: Descrevemos este caso pelo capricho da morfotopografia da dermatose, ao desenvolver-se próxima às comissuras labiais e expandi-se pela região bucal determinando um caráter esteticamente desfavorável. Também pela boa resposta à terapêutica que obtivemos com o ácido retinóico tópico. 


\title{
PO 75 Ictiose folicular com alopécia e fotofobia x ceratose pilar decalvante
}

\author{
AUTORES: Assunção DM, Júnior JRR, Soares ACB, Machado-Pinto J. \\ INSTITUIÇÃO: Santa Casa de Misericórdia de Belo Horizonte
}

INTRODUÇÃo: A Síndrome de Ictiose Folicular com Alopecia e Fotofobia e a Ceratose Folicular Decalvante são duas síndromes recessivas ligadas ao X, que apresentam várias manifestações clínicas comuns, o que torna difícil a diferenciação entre essas duas entidades.

Relato de Caso: L.N.R., masculino, 2 anos e 7 meses, natural e residente em Mariana - MG. HMA: desde 0 nascimento, o paciente apresenta hiperqueratose folicular difusa, mais proeminente nas áreas extensoras das extremidades e alo pécia do couro cabeludo, sobrancelhas e cílios. Com o tempo, desenvolveu uma sensibilidade anormal à luz, vindo a apresentar fotofobia importante. Com 1 ano e 4 meses, foi internado devido a diarréia por intolerância à lactose e desidratação, evoluindo a partir de então com piora do quadro cutâneo. Iniciou com lesões de eczema atópico nas regiões cervical, anal, perianal, pál pebras, queilite angular e queratodermia plantar (calcâneos). Com 2 anos e 2 meses, internou novamente com infecção na cavidade oral e otite. HP: prematuro e baixo peso. HF: tio materno e irmão de 11 meses com quadro semelhante. Histopatologia: hiperqueratose folicular, poucos folículos miniaturizados na derme, ausência de glândulas sebáceas e infiltrado inflamatório discreto. Exames complementares: cariótipo 46 XY, TSH, T4 livre, zinco sérico e imunoglobulinas normais. Tratamento: queratolíticos.

Dıscussão: A síndrome de Ictiose Folicular com Alopécia e Fotofobia (IFAF) compartilha várias característi cas com a Ceratose Pilar Decalvante, incluindo alopécia, hiperqueratose folicular, fotofobia e herança recessiva ligado ao X. No entanto, na Ceratose Folicular Decalvante, a alopécia não é congênita, é localizada e não cicatricial. 0 paciente relatado mostra características das duas síndromes, mas com evolução e achados histopatológicos mais compatíveis com a síndrome IFAF.

Motivo DA APRESENTAÇÃo: Raridade do caso.

\section{PO 76 Hipoplasia dérmica focal mínima no paciente do sexo masculino - Relato de caso}

\begin{abstract}
AUTORES: Oliveira SCC, Oliveira RIFM, Salomão PR, Machado-Pinto J.
INSTITUIÇÃO: Santa Casa de Misericórdia de Belo Horizonte, MG.
\end{abstract}

INTRODUÇÃo: Hipoplasia Dérmica Focal é uma rara enfermidade genética, de provável padrão dominante ligado ao X, caracterizada por lesões cutâneas específicas e associada a anormalidades oftalmológicas, esqueléticas e dentárias. A forma mínima da hipoplasia dérmica focal (envolvimento cutâneo localizado) é descrita numa criança do sexo masculino.

Relato do Caso: L.E.S.M., leucodérmico, 3 anos de idade, natural e procedente de Mateus Leme, MG, apresenta desde o seu nascimento lesões cutâneas apenas na parte posterior do membro inferior direito e dorso do pé direito. Ao exame físico: nota-se a presença de lesão cutânea em padrão linear hipocrômica, levemente eritematosa e atrófica na parte posterior da coxa e perna direita e no dorso do pé direito. Não apresenta alterações dentárias, oftalmológicas e musculoesqueléticas. Exames Complementares: exame radiológico do fêmur direito e esquerdo sem evidências de anormalidades. Exame Histopatológico: presença de alguns adipócitos localizados na espessura da derme e próximos à epiderme. História Familiar: pai e mãe hígidos, não consanguíneos, sem evidência de hipoplasia dérmica focal. Conduta: estudo genético para analisar a presença de mosaicismo e acompanhamento clínico.

Dıscussão: Hipoplasia Dérmica Focal (HDF), também conhecida como Síndrome de Goltz, é uma genodermatose incomum caracterizada por alteração no tecido conjuntivo dérmico associada com outras anormalidades envolvendo os tecidos de origem ectodérmico e mesodérmico. Uma de suas apresentações é a HDF mínima, cuja manifestação é a presença de alterações cutâneas localizadas sem o envolvimento de outros órgãos. Este pode ser um dos motivos que explicaria o número pequeno de casos descritos com esta forma de apresentação. Segundo a literatura, o padrão de herança da síndrome é determinado por gene ligado ao $\mathrm{X}$, letal no sexo masculino homozigótico. Os raros casos encontrados no sexo masculino são explicados pela presença de mosaicismo ou nova mutação. É de grande importância o aconselhamento genético, tendo em vista o modo de herança e a heterogenicidade clínica.

Motivo DA APRESEnTAÇÃo: Raridade desta manifestação clínica no sexo masculino. 


\title{
P0 77 Síndrome de Gorlin: relato de dois casos
}

\author{
AUTORES: $\quad$ Aquino LT, Sternberg F, Ogawa M, Enokihara MY, Cestari SCP. \\ INSTITUIÇÃO: Universidade Federal de São Paulo - Escola Paulista de Medicina - São Paulo, SP.
}

INTRODUÇão: A Síndrome do Carcinoma Basocelular Nevóide ou Síndrome de Gorlin é uma doença autossômica dominante que predispõe a Carcinomas Basocelulares (CBCs), meduloblastomas e fibromas ovarianos. Além dos tumores benignos e malignos associam-se malformações tais como: cistos maxilares e malformações dentárias, depressões pontuadas palmo-plantares características, fenda palatina, fácies característica, estrabismo, disgenesia do corpo caloso, calcificações da foice do cérebro, malformações ósseas, calcificações ectópicas, cistos mesentéricos, macrocefalia e gigantismo.

Hıstórias Cúnicas: Caso 1 - L.N.V.S., 8 anos, masculino, pardo, apresentando desde os 2 anos de idade pápulas acastanhadas assintomáticas, inicialmente na face, com aumento progressivo em número e extensão, acometendo também região cervical e dorso. Ao exame clínico apresentava hipertelorismo, hipodontia, deformidade óssea na região torácica anterior. Ao exame dermatológico notavam-se múltiplas pápulas de aproximadamente 2 a 4 $\mathrm{mm}$ de diâmetro com coloração variando da cor da pele a enegrecidas, distribuídas na região peri-ocular, nasal, região cervical e na porção superior do tronco. Apresentava ainda depressões pontuadas nas palmas bilateralmente. Caso 2 - V.S.G., 14 anos, masculino, pardo, com lesões na região cervical desde um ano de idade. Aos dois anos de idade teve meduloblastoma tratado com radioterapia. Na mesma época surgiram pápulas hipercrômicas em diversas regiões do corpo. Aos 11 anos apresentou quadro de leucemia mielóide aguda do subtipo M3, tratada com quimioterapia. Ao exame apresentava inúmeras pápulas com coloração variando do acastanhado ao marrom escuro, de tamanhos variados, localizadas no pescoço, abdômen e, em menor número, na fronte e borda do couro cabeludo. As lesões apresentavam limites bem definidos e múltiplas formas.

EXames Complementares: Exérese de lesões com diversos aspectos clínicos, de ambos os pacientes. Ao exame histopatológico todas as lesões eram de carcinoma basocelular.

Discussão e Conclusão: A Síndrome de Gorlin é um distúrbio raro e relativamente grave, de difícil abordagem terapêutica pela multiplicidade dos tumores. Além dos carcinomas de pele, um dos pacientes já apresentou duas outras neoplasias, uma delas aparentemente não correlacionada à síndrome (associação ao acaso? influência da radioterapia prévia?). 0 paciente do caso 1 encontra-se em investigação diagnóstica por apresentar também características sugestivas de Síndrome de Noonan (baixa implantação de orel has, pescoço curto, pectus carinatum, retardo mental leve, criptorquidia bilateral, déficit auditivo). Trata-se portanto de um paciente com fenótipo clínico de Síndrome de Noonan (aguarda confirmação de mutação característica) associada a Síndrome de Gorlin. JUSTIFICATIVA PARA APRESENTAÇÃo: Enfocar duas diferentes apresentações clínicas de doença rara, com manifestações exuberantes.

\section{PO 78 Doença de Darier}

\author{
AUTORES: Nicoliello JM, Vasconcelos MRA, Ordones DRS, Michalany NS, Yamashita JT. \\ INSTITUIÇÃO: UNIFESP/EPM - São Paulo, SP
}

INTRODução: A Doença de Darier (ou keratosis follicularis), descrita por White e Darier em 1889, é genodermatose rara, de herança autossômica dominante caracterizada por pápulas queratósicas em óstios foliculares. Inicia-se na infância e agrava-se com a idade. A doença é causada por mutação no gene ATPA2 e cromossomo 12q24.1.

Relato DE CASO: Trata-se de relato de três casos de Doença de Darier de uma mesma família. Caso A: H.B.A.E., 22 anos, masculino; ao exame dermatológico apresentava pápulas queratósicas normocrômicas e acastanhadas no dorso das mãose pés e múltiplas micropápulas queratósicas na região plantar. Caso B: N.A.E., 48 anos, feminino; ao exame apresenta pápulas queratósicas acastanhadas, confluentes na região submamária, hiperqueratose plantar bilateral, hiperqueratose subungueal, onicodistrofia e onicorrexe nos quirodáctilos e pododáctilos. Pápulas esbranquiçadas no palato duro. Caso C: N.C.G., 53 anos, feminino, em tratamento com acitretina $25 \mathrm{mg} / \mathrm{dia}$ com melhora das lesões. Ao exame físico apresenta eritema e descamação na face e região palmoplantar. Realizada biópsia dos casos A e B que revelou Doença de Darier.

Dıscussão: $O$ diagnóstico da doença de Darier é clínico, sendo confirmado por meio do exame histopatológico que revela hiperqueratose, disqueratose (corpos redondos e grãos), presença de lacunas e prolife- 
ração irregular de pápulas dérmicas para o interior dessas lacunas. As pápulas queratósicas distribuem-se de preferência nas áreas seborréicas, mas pode haver comprometimento das mucosas oral e genital. 0 acometimento da mucosa oral é raro, sendo na forma de pápulas esbranquiçadas localizadas em mucosa, gengiva e palato duro, devendo ser diferenciada da leucoplasia. As unhas apresentam sulcos longitudinais, hiperqueratose, são frágeis e quebradiças. Em região palmoplantar, podem ocorrer pequenas pápulas queratósicas. As lesões papulosas acrais podem constituir a primeira manifestação da doença, sendo debatida a existência isolada da acroqueratose de Hopf como patologia individual.

Objetivo da ApresentaÇÃo: Demonstrar a ocorrência familiar desta genodematose e ilustrar a variabilidade das lesões dermatológicas entre os indivíduos, mesmo entre os de uma mesma família, e a evolução das lesões conforme o passar dos anos.

\title{
PO 79 Síndrome de Wiskott-Aldrich
}

AUTORES: Pinto TAB,Tenório MDL, Mendes CJTA, Soares FES, Cardoso AEC.
INSTITUIÇÁO: Serviço de Dermatologia do Prof. Alberto Cardoso/HUPAA - Maceió, AL.

INTRODUÇÃo: A síndrome de Wiskott-Aldrich (SWA) é um distúrbio recessivo ligado ao cromossomo X que acomete em quase sua totalidade o sexo masculino. Caracteriza-se por defeitos imunológicos, trombocitopenia e lesões cutâneas tipo eczema.

Caso Cúnico: R.S.S., 16 anos, masc., branco, procedente de Passo de Camaragibe, AL. Paciente acompanhado há dois anos em nosso serviço, com quadro de lesões cutâneas disseminadas, pruriginosas, predominando em áreas flexoras, região cervical posterior e face. História de escabiose recorrente e infecções de repetição (otites, pneumonia, diarréia) desde a infância. Perda da visão do olho esquerdo há um ano. Não há relatos de casos na família. Exame clínico (03/2005): paciente com desenvolvimento físico não compatível com a idade, emagrecido, mucosas hipocoradas, abdômen globoso com hepatoesplenomegalia. Exame dermatológico: placas eritemato-descamativas disseminadas, algumas liquenificadas, predominando em áreas flexoras, região cervical posterior e face. Pápulas e crostas em abdômen, genitália e mãos compatíveis com quadro de escabiose. Couro cabeludo com intenso eritema e descamação. Unhas frágeis, quebradiças. Biópsia e histopatológico em lesão eczematizada do braço direito, compatível com dermatite espongiótica. Exames laboratoriais (11/2004): Ht: 28,8\%, Hg: 9,6, plaq.: 52.900, leuc.: 2530, IgA: 130 mg/dl, IgG:1.141 mg/dl, IgM: 80 mg/dl, IgE: 531UI/ml. (03/2005): Ht: 30,8\%, Hg:10,2, plaq.: 52.000, leuc.: 1.890 EAS: 30 piócitos/campo e presença de leveduras. Foi feito o diagnóstico de SWA. O paciente é visto em regime ambulatorial, tratando as infecções recorrentes, faz uso de complexos vitamínicos e recebe acompanhamento hematológico.

Discussão: Esta síndrome manifesta-se inicialmente nos primeiros meses de vida com sangramento, especialmente diarréia sanguinolenta. Infecções recorrentes são comuns por germes encapsulados, ocorrendo piora com o avançar da idade devido a deterioração de função das células T. A dermatite atópica é vista em $80 \%$ dos pacientes, podendo ser muito grave. A trombocitopenia é persistente, estando a contagem diminuída desde o nascimento, o que decorre de defeito estrutural das plaquetas, que são de dimensões menores. Hepatoesplenomegalia é comum. Há níveis baixos de IgM, níveis normais ou elevados de IgA e IgG e níveis elevados de IgE. Antibióticos sistêmicos, transfusões de plaquetas e plasma, gamaglobulinas sistêmicas, são terapêuticas citadas, porém o transplante de medula óssea é o tratamento de escolha para esses pacientes. Relatamos um caso com clínica, laboratório e evolução característica desta afecção.

Motivo da APRESEnTAÇÃo: Raridade do caso.

\section{P080 Relevância das manifestações dermatológicas no diagnóstico precoce da esclerose tuberosa}

\author{
AUTORES: Saraiva LES, Medeiros VA, Azevedo e Silva MC, Spinato DR, Fernandes NC. \\ INSTITUIÇÃO: Serviço de Dermatologia. Instituto de Puericultura e Pediatria Martagão Gesteira. Universidade \\ Federal do Rio de Janeiro, RJ.
}

INTRODuÇão: A Esclerose Tuberosa (ET) é uma desordem autossômica dominante com manifestações clínicas variadas. É caracterizada pela tríade: epilepsia, retardo mental e formação de hamartomas em múltiplos órgãos. As manifestações dermatológicas que podem ser encontradas são: angiofibromas faciais, fibromas 
periungueais (tumores de Köenen), máculas hipomelanóticas (ash leaves), pigmentação em confete, placas de Shagreen, fibromas de gengiva, pits dentais, máculas café com leite e poliose.

ReLATO DE CASO: Escolar do sexo feminino, 8 anos, com lesões cutâneas desde os 2 anos que se caracterizavam por pápulas amarelo-avermelhadas, amolecidas e assintomáticas na região centro-facial; múltiplas máculas hipocrômicas em forma de folha no tronco e membros inferiores; e placas irregulares, infiltradas e hipercrômicas em regiões cervical, frontal e dorsal. Crises convulsivas há 4 anos. Ausência de casos semelhantes na família. Encaminhada ao serviço ainda sem diagnóstico. Havia realizado previamente tratamento para vitiligo sem sucesso. A paciente apresentava angiofibromas faciais, mais de três máculas (ash leaves) e placas de Shagreen, quadro cutâneo exuberante para a idade da paciente e suficiente para o diagnóstico de ET. Foi encaminhada às especialidades para investigação de achados associados e está sendo acompanhada pela Dermatologia.

Dıscussão: As lesões dermatológicas estão presentes inicialmente em 83,3 \% dos casos e chegam a 98,7\% com a evolução da doença. As máculas hipomelanóticas representam as lesões mais comuns e precoces da doença. A idade média de surgimento dos angiofibromas e placa de Shagreen é entre 2,6 - 6 e 8,1 anos respectivamente. A presença das máculas hipomelanóticas implica maior chance de associação com epilepsia. 0 vitiligo representa uma das principais patologias implicadas no erro diagnóstico.

MotIVo DA APRESENTAÇÃo: Ressaltar a importância dos achados cutâneos no diagnóstico precoce da doença permitindo pronta investigação de envolvimento sistêmico.

\title{
P0 81 Síndrome de Rothmund Thompson: relato de um caso
}

\author{
AUTORES: Cunha PCAS, Lima SS, Rebello M, Passos AP, Rocha MM. \\ INSTITUIÇÃO: Departamento de Dermatologia, Hospital Infantil Darcy Vargas - São Paulo, SP.
}

INTRODução: A Síndrome de Rothmund Thompson, também conhecida como Poiquilodermia Congênita, é um raro distúrbio recessivo de fotossensibilidade que se manifesta, geralmente, no primeiro ano de vida, por meio de lesões poiquiloidérmicas principalmente em áreas expostas, com desenvolvimento subseqüente de ceratoses e carcinomas espinocelulares na adolescência.

ReLATO do CASO: Paciente L.A.J.C., 22 anos, sexo feminino, negra, natural e procedente de São Paulo, apresentava desde os 2 anos de idade lesões bolhosas principalmente em mãos, pés e cotovelos, associadas a xerose e manchas hipercrômicas em áreas fotoexpostas. Vale ressaltar que em sua história familiar encontramos pais primos em 1으 grau e dois irmãos apresentando também o mesmo quadro. Ao exame físico observou-se a presença de lesões escleridiformes e ictiosiformes generalizadas, máculas hiper e hipocrômicas por todo corpo, hipercromia facial, má oclusão dentária, mãos com esclerose cutânea, afinamento dos dedos, unhas pequenas e distróficas e ceratodermia plantar. Foram solicitados os seguintes exames complementares; Hemograma normal, $\mathrm{TGO}=20 ; \mathrm{TGP}=27 ; \mathrm{DHL}=131$, FAN: não reativo, Anti-SM: não reativo, Anti-RNP: não reativo, CPK normal, Pesquisa de porfirinas urinárias: negativa. Ao exame histopatológico: atrofia cutânea evidente, degeneração hidrópica basal e melanófagos dispostos em faixas na derme reticular; fechando, assim, o diagnóstico. Dessa forma foi estabelecido o único tratamento possível, sintomático e acompanhamento periódico da evolução e possíveis complicacões.

Dıscussão: Como evidenciado neste caso, a Síndrome de Rothmund Thompson é uma afecção familiar, hereditária autossômica recessiva, a qual pode apresentar clinicamente, além de todas manifestações presentes nesta paciente, hipotricose, catarata, hipogonadismo, retardo mental, e ainda em alguns casos osteossarcoma associado.

Motıvo DA APRESENTAÇão: Dada a raridade da síndrome aqui apresentada e a gravidade de seu quadro clínico e evolução, destaca-se a importância de sua exposição, com o objetivo de auxiliar não somente no diagnóstico de novos casos e seu pronto tratamento (sintomático), mas, sobretudo, no acompanhamento e diagnóstico precoce de possíveis complicações graves como catarata e neoplasias (CEC e osteossarcoma).

\section{P082 Acropigmentação reticulada de Kitamura - Relato de 3 casos}

\author{
AUTORES: Meissner MCG, Mendes MF, Takaoka LE, Bedrossian AAD, Silva HC. \\ INSTITUIÇÃO: Serviço de Dermatologia da UEL e da Sociedade Filantrópica Humanitas - Londrina, PR.
}

INTRODuÇão: A acropigmentação reticulada de Kitamura é uma genodermatose rara, com herança autossô- 
mica dominante, e descrita por Kitamura e Akamatsu em 1943. Caracteriza-se por máculas pigmentadas levemente atróficas que acometem as superfícies extensoras de mãos e pés. Os autores relatam três casos de acropigmentação reticulada da Kitamura em uma mesma família.

Relato de Casos: Caso 1. V.L.Y., feminina, 14 anos, procedente de Assaí, PR, refere que há +/- 13 anos apresenta manchas em mãos e pés. Ao exame observam-se máculas hipercrômicas puntiformes em face extensora de membros superiores e inferiores. Caso 2: C.H.H.Y., 11 anos, masculino, irmão da paciente descrita anteriormente, queixando-se de manchas escuras e assintomáticas em mãos. Caso 3: H.W.Y., feminina, 44 anos, mãe dos pacientes descritos, apresentando há longa data máculas hiperpigmentadas em dorso de mãos. Orientado fotoproteção para os três pacientes.

Discussão: A acropigmentação reticulada de Kitamura (ARK) caracteriza-se por máculas hiperpigmentadas, reticuladas, ligeiramente atróficas, poligonais, principalmente em superfícies extensoras de mãos e pés. As máculas hipercrômicas da acropigmentação reticulada diferenciam-se das efélides pelo padrão retiforme e pela atrofia discreta. Interrrupções das linhas da pele em áreas palmo-plantares (pits) também são características. A hiperpigmentação aumenta com a exposição solar e com a idade. 0 exame anatomopatológico apresenta atrofia da epiderme e projeções epiteliais com depósito de melanina. Os principais diagnósticos diferenciais são com Doença de Dohi e Doença de Dowling-Degos (DDD). Na Doença de Dohi ou Discromatose simétrica hereditária, as lesões têm a mesma distribuição, não são atróficas e encontram-se máculas leucodérmicas. Há descrições na literatura de acropigmentação reticulada de Kitamura e Doença de Dowling-Degos num mesmo indivíduo, por essa razão muitos autores acreditam que sejam expressões clínicas diferentes de uma mesma entidade. As principais diferenças entre as duas patologias são: hiperpigmentação acral na ARK e flexural na DDD; lesões atróficas na ARK e papulares na DDD; idade de início das lesões, infância na ARK e idade adulta na DDD; pits palmares e atrofia de epiderme na ARK.

MOTIVO DA APRESENTAÇÃo: Genodermatose rara.

\title{
P083 Epidermodisplasia verruciforme - Relato de caso
}

\author{
AUTORES: Meissner MCG, Gon AS, Bedrossian AAD, Sonnberger JCN, Reis CRC. \\ INSTITUIÇÃO: Serviço de Dermatologia da UEL - Londrina, PR.
}

INTRODuÇÃO: A Epidermodisplasia Verruciforme (EV) é uma genodermatose rara, descrita por Lewandowski e Lutz em 1922. Os pacientes portadores de EV apresentam suscetibilidade para infecções cau sadas por certos tipos de papiloma vírus humano (HPV), alguns com capacidade oncogênica.

Relato de CASO: C.F.S., feminina, 38 anos, procedente de Londrina, PR, encaminhada ao serviço por apresentar desde a infância "verrugas" em mãos. Na evolução aumentaram em número e tamanho e extenderam-se para outras partes do corpo. Refere surgimento de lesões semelhantes em locais de trauma. Irmã com lesões similares. Ao exame apresenta uma dermatose disseminada, bilateral, simétrica, com pápulas e máculas eritematosas e hipocrômicas, 0,5 a $2 \mathrm{~cm}$ de diâmetro, localizadas principal mente em áreas fotoexpostas. Exames complementares dentro da normalidade. A biópsia de pele demonstrou hiperceratose, hipergranulose, acantose, células volumosas e frouxas na epiderme com efeito citopático viral. Resultado compatível com EV. Os dados clínicos e histopatológicos confirmaram o diagnóstico de EV. O tratamento com Acitretina foi recusado pela paciente que deseja engravidar. Orientado fotoproteção, Levamisol 300 mg/semana e reavaliações freqüentes.

Discussão: A EV é um modelo de carcinogênese induzida por vírus. A persitência da infecção pelo HPV é resultado de um defeito imunogenético que determina a geração de várias citocinas que impedem que o sistema imune do paciente reconheça e rejeite os HPV. Na maioria dos casos a transmissão é autossômica recessiva, mas já foram descritos casos de herança ligada ao X. As manifestações cutâneas surgem na infância, são polimórficas, semelhantes a verrugas planas, máculas e pápulas eritematosas, hipo ou hipercrômicas semelhantes a pitiríase versicolor. Transformação maligna pode ocorrer em metade dos pacientes após a quarta década, principalmente em áreas fotoexpostas. Até o momento não existe um tratamento espcífico para EV. Métodos ablativos químicos ou cirúrgicos são contraindicados devido à distribuição generalizada das lesões. 0 uso de derivados de vitamina A tem sido recomendado. Imunoterapia com Interferon sistêmico ou intralesional em doses que variam de 1 a 9 milhões tem sido tentada. A combinação de Acitretina e Interferon alfa 2a foi descrita, mas a manutenção da terapia se faz necessária para evitar recaídas. 0 tratamento com cimetidina $40 \mathrm{mg} / \mathrm{kg} / \mathrm{dia}$ em 3 doses apresentou boa resposta clínica e poucos efeitos colaterais. Devido ao risco de transformação neoplásica é importante fotoproteção, vigilância periódica de lesões suspeitas, aconselhamento genético e apoio psicológico ao paciente. Motivo DA APRESENTAÇÃo: Dermatose rara e com alto risco de transformação neoplásica. 


\title{
P084 Acrodermatite enteropática: concentração sérica de zinco normal descarta diagnóstico? - Relato de caso
}

\author{
AUTORES: $\quad$ Ribeiro JAS, Tristão RJ, Pelegrinelli FFF, Freitas GHO, Naves MC. \\ INSTITUIÇÃO: Faculdade de Medicina do Triângulo Mineiro - Uberaba, MG.
}

INTRODUÇão: Acrodermatite Enteropática ( $\mathrm{AE}$ ), desordem hereditária autossômica recessiva, é caracterizada pela tríade, que se manifesta em apenas $20 \%$ dos pacientes, de dermatite, diarréia persistente e alopecia. Apresenta-se, freqüentemente, por lesões periorificiais (face, períneo e regiões acrais), em placas erosivas, eritematosas, crostosas com descamação lembrando a psoríase e a dermatite seborréica, por vezes, evoluindo com bolhas e pústulas. Tal distribuição patognomônica sugere a dermatite por deficiência de zinco e a suplementação deste oligoelemento promove, marcadamente, a regressão do quadro clínico.

RELATO de CAso: Lactente de 57 dias de vida, nascido a termo, porém pequeno para a idade gestacional, em aleitamento materno exclusivo, iniciou há 30 dias placas eritêmato-descamativas e crostas em face com predomínio periorificial, evoluindo, posteriormente para membros, tronco e períneo. Fez uso de vários medicamentos tópicos e sistêmicos sem melhora. Peso de 3.100 gramas. Anemia importante (hemoglobina= $\pm 5,9 \mathrm{~g} \%$ ). As dosagens de zinco sérico obtidas foram de 75,9 $\mathrm{g} / \mathrm{dL}$ na lactente e $62,5 \mu \mathrm{g} / \mathrm{dL}$ na mãe - normalidade: 70 a $120 \mu \mathrm{g} / \mathrm{dL}$. Iniciado zinco quelado $4 \mathrm{mg} / \mathrm{dia}$, com regressão drástica das lesões após duas semanas de tratamento.

Discussão: Alguns autores relatam a competição entre zinco e ferro na absorção pelo trato intestinal, podendo levar à deficiência de um ou de outro. Talvez a diminuição importante do competidor preponderante (o ferro) possa privilegiar a absorção do zinco, gerando uma zincemia normal. São descritos casos de $\mathrm{AE}$ durante o período neonatal em crianças de baixo peso ao nascimento e prematuras, que exigem maior demanda de zinco para seu desenvolvimento. Fenômeno raro, a AE sem hipozincemia também é descrita, causada pela dificuldade de ligação enzimática do zinco, permitindo sua absorção, porém prejudicando sua distribuição. Autores sugerem que a suplementação de zinco seja entre 5 e $10 \mathrm{mg} / \mathrm{dia}$.

Motivo DA APRESENTAÇÃo: Raridade do caso e nível de zinco sérico dentro dos limites da normalidade.

\section{P0 85 Síndrome de Vogt-Kayanagi-Harada: relato de caso}

\author{
AUTORES: $\quad$ Cucé LC, Ferolla AC, Botelho EC, Vianna PL. \\ INSTITUIÇÃO: Universidade de Santo Amaro - São Paulo-SP
}

INTRODUÇÃo: A Síndrome de Vogt-Kayanagi-H arada é uma doença multisistêmica aparentemente rara, caracterizada por vitiligo, poliose, uveíte, disacusia e alopecia. Acomete ambos os sexos, o pico de freqüência ocorre aos 30 anos, mas relatou-se início dos 10 aos 52 anos de idade A Síndrome clássica se manifesta em três fases: a primeira é a fase meningoencefalítica, a segunda é a fase oftálmica-otológica e a terceira é a fase convalescente. 0 diagnóstico se baseia nas anormalidades oculares, anormalidades do SNC e nas lesões de pele. $O$ diagnóstico diferencial mais importante é o vitiligo. $O$ tratamento das anormalidades oculares é com esteróides e pode previnir a progressão da cegueira, já o tratamento do vitiligo apresenta opções variadas.

Relato do Caso: Relatamos um caso de criança, 6 anos, sexo feminino, com mácula acrômica periocular direita acompanhada de poliose ciliar desde os 3 anos de idade e alteração da coloração da íris que se apresenta metade acastanhada e metade azulada. A criança apresenta poliose do couro cabeludo e mácula hipocrômica em dorso. Foi realizado o exame oftalmológico que apresentou apenas alteração na coloração da íris do olho direito, mas não apresentou alterações ao exame do fundo de olho e os exames neurológicos e psicopedagogo não apresentaram alterações.

Dıscussão: A Síndrome de Vogt-Kayanagi-Harada é rara, acomete vários órgãos, pele, sistema nervoso e ocular, e seu aparecimento é comum ao redor dos 30 anos. Relatamos uma criança do sexo feminino, 6 anos, que apresenta alterações cutâneas e oculares relatadas na literatura, mas não apresenta alterações neurológicas, o que não significa que com o avançar da idade a doença não possa progredir.

Motivo DA APRESEnTAÇÃo: É a raridade da doença e a manifestação em criança com alterações cutâneas e oculares. 


\title{
P086 Síndrome de Goltz
}

AUTORES: Vasconcelos XT, Accioly Filho JW, de Oliveira TR, Viana VFV, Vasconcelos VV.
INSTITUIÇÃO: Serviço de Dermatologia - Hospital Universitário Walter Cantídio - Fortaleza - Ceará, CE.

INTRODução: Síndrome de Goltz ou Hipoplasia Dérmica Focal é uma genodermatose rara, caracterizada por anormalidades de origem ectodérmica e mesodérmica. As características cutâneas são placas atróficas discrômicas envolvendo o tronco e as extremidades, seguindo as linhas de Blaschko. Podem existir ainda alterações dentárias, oculares e ósseas.

ReLATO do CASO: Paciente, sexo feminino, 14 anos, procurou a Dermatologia por apresentar alterações cutâneas e assimetria facial desde o nascimento, sem casos semelhantes na família. Relatou que aos 3 anos de idade, foram realizadas cirurgias corretivas para sindactilia de segundo e terceiro pododáctilos direitos, hérnia abdominal epigástrica e obstrução completa de ducto nasolacrimal esquerdo. Exame dermatológico revelou placas atróficas com áreas de hipo e hiperpigmentação, seguindo linhas de Blaschko nos membros superiores e predominantemente do lado esquerdo da face e tórax, com padrão zosteriforme. Exame histopatológico destas lesões evidenciou derrame pigmentar. Apresentava unhas distróficas. Após avaliações odontológica e osteomuscular, foram encontrados anodontia, dentes inclusos impactados e dentes supranumerários, escoliose dorso-lombar e osteopenia difusa. Exame oftalmológico sem alterações. As características clínicas e histopatológicas sugerem o diagnóstico de Síndrome de Goltz.

Discussão: Hipoplasia Dérmica Focal é preponderante no sexo feminino, sugerindo herança ligada ao $X$, entretanto a maioria dos casos é de natureza esporádica. Trata-se de um caso com alterações cutâneas típicas, além das anormalidades dentárias e músculo-esqueléticas que ocorrem em $80 \%$ dos casos. Em $60 \%$ dos casos, não existem alterações oculares (como no caso descrito).

MOTIVO DA APRESENTAÇÃo: Raridade do caso.

\section{P087 Comedões disqueratóticos familiares: relato de caso}

\author{
AUTORES: $\quad$ Reis CRC, Sonnberger JCN, Minelli L, Meissner M, Bedrossian A. \\ INSTITUIÇÃO: Serviço de Dermatologia da UEL - Londrina, PR.
}

INTRODUÇÃo: Os autores apresentam caso de comedão disqueratótico familiar, com poucos casos descritos. ReLATO DE CASO: L.M.S., 16 anos, feminina, fototipo IV, estudante, natural e procedente de Londrina, PR, com espinhas em dorso há 2 anos, que estão aumentando em número e extensão. Afirma que o pai, avô paterno e tios apresentam lesões semelhantes. Exame físico: comedões abertos e fechados, além de algumas pápulas e pústulas em dorso, face e colo. Exames complementares: anatomopatológico: invaginação com acantose e disqueratose epidermica - "poro gigante/comedão gigante". Hemoglobina=12,6 g/dl, Hematócrito $=37,6 \%$, leucograma $=5.800$, com diferencial normal, plaquetas $=374.000 /$ ul, funções renal e hepática=normais. Tratamento inicialmente tópico com retinóides e posteriormente sistemático com isotretinoina - $30 \mathrm{mg} / \mathrm{dia}(0,6 \mathrm{mg} / \mathrm{d})$, apresentando melhora gradual das lesões.

Dıscussão: Relata-se caso compatível ao descrito na literatura como comedões disqueratóticos familiares. Trata-se de uma rara genodermatose autossômica dominante, que se manifesta na adolescência ou adulto jovem como pápulas queratóticas em extremidades e raramente em tronco e face, podendo cursar ocasionalmente com inflamação e prurido local. 0 tratamento com crioterapia e retinóides tem mostrado eficácia. Motivo da APRESENTAÇÃo: Raridade de casos descritos, além de apresentar como diagnósticos diferenciais doenças comuns à clínica dermatológica.

\section{DEPARTAMENTO DE CABELOS E UNHAS}

\section{P088 Nevo melanocítico atípico subungueal}

\author{
AUTORES: Bolzani FCB, Sales PPN, Stefani M, Charlin R, Kac BK. \\ INSTITUIÇÃO: Instituto de Dermatologia Professor Rubem David Azulay da Santa Casa de Misericórdia do RJ
}

